DOE/ER/45401--3

DE92 019744

\title{
TECHNICAL PROGRESS REPORT
}

\author{
TO THE DEPARTMENT OF ENERGY
}

Tiple:

Measurements of Crystal Growth Kinetics at Extreme Deviations from Equilibrium

Award \#:

DE-FG()2-89ER45401

Period of Award: 1 September 1990 - 31 August 1991

Grantee:

President \& Fellows of Harvard College

Office for Sponsored Research

Holyoke Center, Room 440

1350 Massachusetts Avenue

Cambridge MA 02138

P.I.:

Michael J. Aziz

Associate Professor of Materials Science

Division of Applied Sciences

Harvard University

29 Oxford St.

Cambridge MA 02138

(617) $495-9884$

Date: July 14,1992

\section{DISCLAIMER}

This report was prepared as an account of work sponsored by an agency of the United States Government. Neither the United States Govertiment not any agency thereof, nor any of their employees, anakes any warranty, express or implied, or assumes any legal liability or responsibility for the accuracy. completeness, or usefulness of any information, apparatus, product, or process disclosed, or represents that its use would not infringe piivately owned rights. Refer. ence herein to any specific commercial product, process, or service by rrade name, trademark, manufacturet, or otherwise does not mecressarily constitute or imply its endorsement, recom-

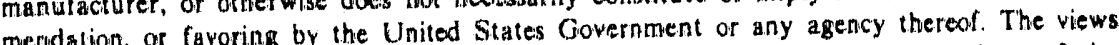
and opinions of authors expressed herein do not necessarily state or reflect those of the United States Government or any agency thereof.

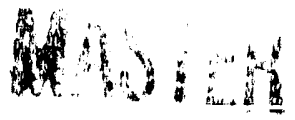




\begin{abstract}
We have measured solute trapping of several solutes in Al during rapid solidification. We have also made preliminary measurements of solute trapping of As in Si, trapped 20 atomic percent As in Si, and made a preliminary measurement of the $\mathrm{T}_{0}$ curve in Si-As.
\end{abstract}

\title{
1. RESEARCH PROGRESS FOR 1991.92
}

We have managed to solute-trap up to 20 atomic percent arsenic onto substitutional lattice sites in Si, resulting in highly concentrated solutions. In addition, the $k(v)$ function, which we are in the process of measuring for dilute solutions, undergoes a transirion from equilibrium partitioning to complete solute trapping over a velocity range that appears to be experimentally measurable, as shown in Figs. 1-3. Arsenic is the only dopant in Si (that we have found so far) that is sluggish enough to be completely trapped at "routine laser-annealing" velocities of $1-5 \mathrm{~m} / \mathrm{s}$. As shown in Fig. 2, we can slow down the velocities enough to observe the effects of significant partitioning at the interface - a "spike" of arsenic that has been zone-refined out to the surface during solidification. Obviously, the $k(v)$ data in Fig. 3 are preliminary. but $k$ appears to rise too steeply with $v$ to fit the concinuous growth model. More accurate measurements are in progress to resolve this issue.

The thermodymamics of supersaturated Si-As are important as input to the kinetic nodels for the velocity-undercooling function. We expect to the able to model the thermodynamics to sufficient accuracy if we know the $T_{0}$ curve (the temperature, as a function of composition. at 


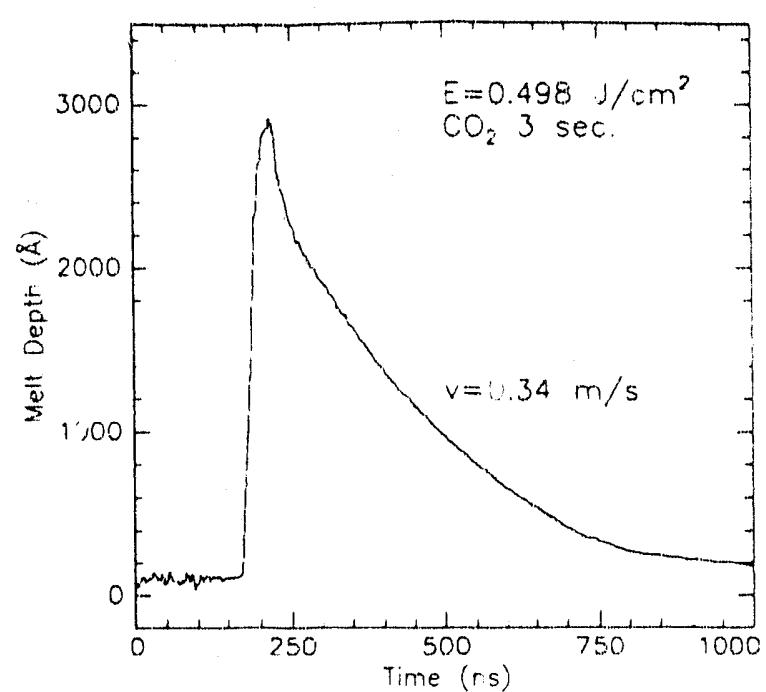

Figure 1. Measured melt depth is time for plilsed-laser-melted dilute Si-As alloy thin film on $\mathrm{SiO}_{2}$. Sample was heated from back by $\mathrm{C} \cdot \mathrm{W} \mathrm{CO}_{2}$ laser immediately prior to pulsed laser melting in order to reduce solidification velocity. Measured velocity of approximately $0.34 \mathrm{~m} / \mathrm{s}$ is d'termined from slope of curve. Spike ai peak of trace is artifact of electromagnetic interference from laser firing, which disappears som after solidification begins.

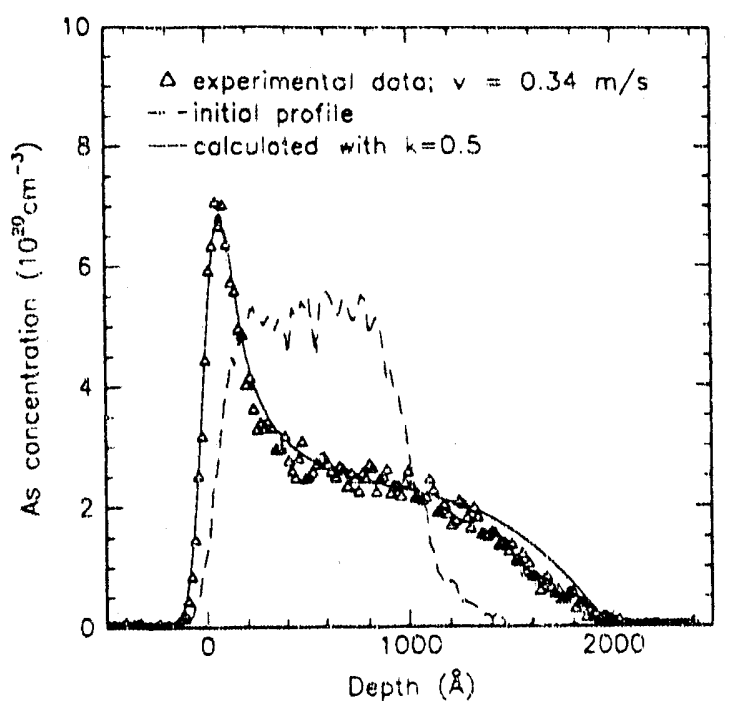

Figure 2. Arsenic depth profiles measured by RBS before and after pulsed laser melting and solidification at $0.3 .4 \mathrm{~m} / \mathrm{s}$. Solid chrve is simulation using measured time. dependence of melt depth. measured initial profile, and best-fit partition coeffirien of $k=0.5$

which solid and liquid solutions of identical composition have the sime Gibbs free energy) for the Si-As alloy. We made a measurement of the $T_{0}$ curve in collaboration with J.A. Knapp at Sandia Laboratories. He uses a scanned pulsed line-source e-bearn to melt thin films on sapphire. The heating rate is too rapid for precipitation to occur before the $T_{0}$ temperature is crossed, at which point melting occurs quite rapidly. The peak temperature vs. distance from the center of the line is carefully calibrated, and the width of the melted region is used to deiermine the peak temperature at the rnelting threshold. The advantages of the e-beam source are that the reflectivity for both solid and liquid is known (it's zero) and for any thin film on sapphire, on the rime scale of the experiment, the known thermal properties of the sapphire substrate completely dominate the unknown properties of the film. As shown in Fig. 4, the $\mathrm{T}_{0}$ curve we obtained for Si-As is different than the $\mathrm{T}_{0}$ curve obtained by Pietro Baeri and his graduate student, Riccardo Reitano, 


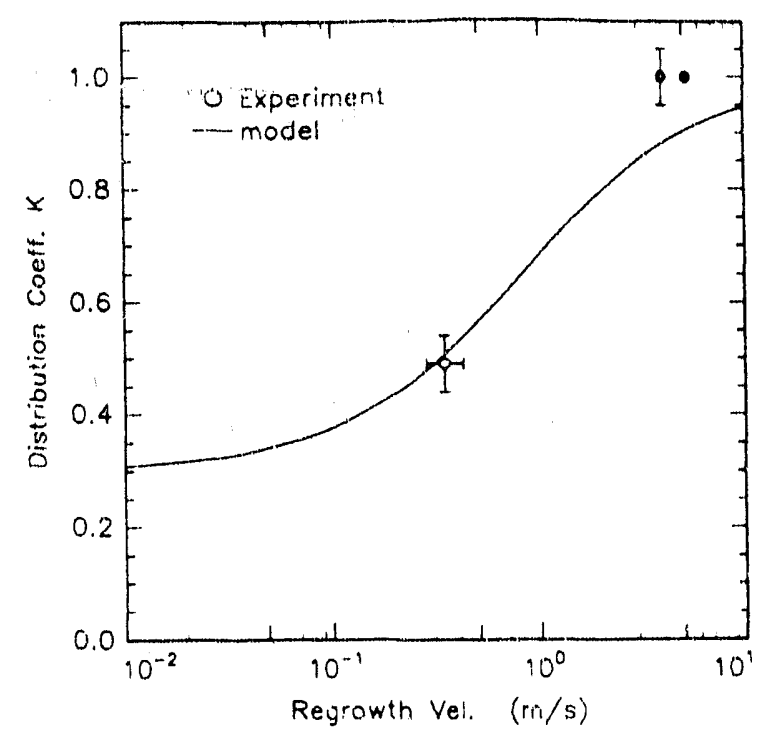

Figure 3. $k(v)$ function for Is in Si. Point at $0.34 \mathrm{~m} / \mathrm{s}$ measured on $\mathrm{Si}-\mathrm{on}-\mathrm{SiO}_{2}$ with $\mathrm{CO}_{2}$ heating; points at 4 and $5 \mathrm{~m} / \mathrm{s}$ measured on Si-on-sapphire with no heating. Curve. fit of continuous growth model with vo $=$ $0.82 \mathrm{~m} / \mathrm{s}$. may not rise steeply enough to account for experime'nt. More thorough measurements will sette the issue.

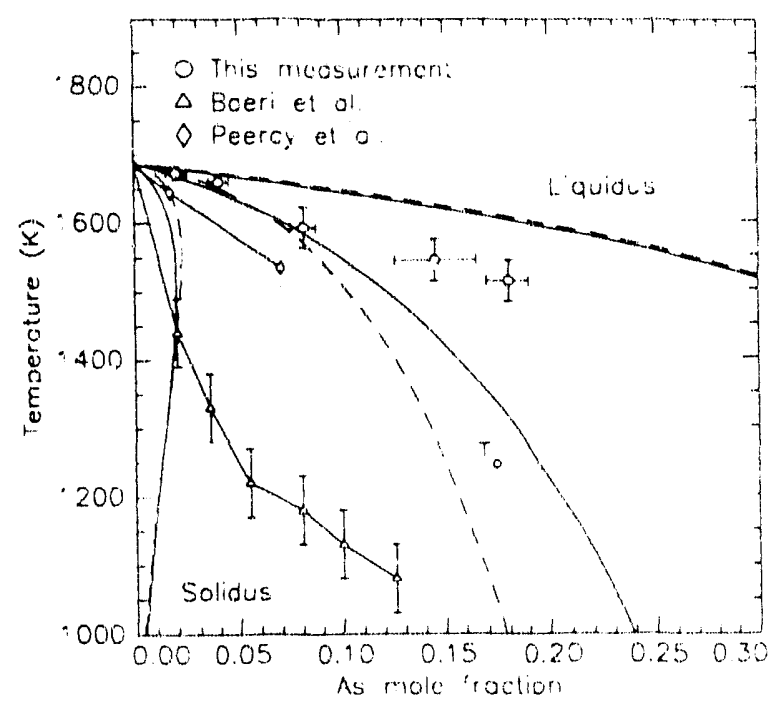

Figure 4. Measured $T_{0}$ temperatures and calculated phase boundaries and $T_{0}$ curve in Si-As allows. Solid and broke'n curves are calculated phase boundaries and $T_{0}$ curves using two different assumptions about the thermodinamic paramelers.

who used pulsed laser melting techniques. It also differs from another measurement by Peercy et al.. Dr. Reitano, supported by an Italian National Postdoctoral Fellowship, recently joined our group after obtaining his Ph.D. and is resolving the differences between the $T_{0}$ curves.

\subsection{Solute Trapping in Metals}

We are now making the world's first measurements of solute trapping in metallic systems.

This is much more difficult than our eartier experiments that led to a pretty thorough understanding of the solute trapping process in silicon. But it is quite important to get data in metals. In contrast to silicon, where the change in structure from a covalent solid to a metallic melt is a theorist's nightmare, in metals we are getting to the point where first-principles calculations of the struciure and properties of the crystal-melt interface are possible. Such calculations can already be done in 
fic and hep metals with the embedded-atom method (though it is not first-principles, it is less phenomenological than the simple "continuous growth model").

At present, we have managed to obtain nonequilibrium partition coefficients at a single velocity for $\mathrm{Sn}, \mathrm{Ge}$, and $\mathrm{Cu}$ in $\mathrm{Al}$ and a couple of solutes in $\mathrm{Ni}$, as shown in Fig. 10, and over a small velocity range for Ge in Al. We have had to work hard to contrc nsi-solidification solidphase diffusion, which was altering our Al-Sn and Al-Ge depth profiles in some cases when the samples were preheated with a $\mathrm{CO}_{2}$ laser.

Figure 5. RBS depth profiles of $20 \mathrm{~PB}$ in 1800 A Ni film before and after pulsed laser melting and solidification. Lines show computer simulations used to determine partition coefficient. Best fit is $k(1.2 \mathrm{~m} / \mathrm{s})=0.12$ and $D_{\text {liq }}=4.0 \times 10^{-5} \mathrm{~cm}^{2} / \mathrm{sec}^{\mathrm{e}}$.

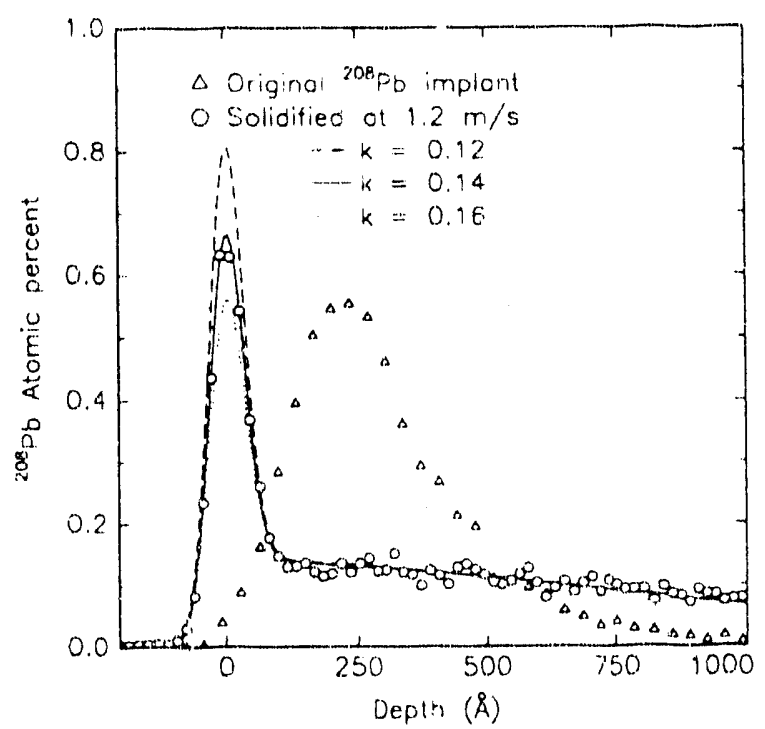


page 6

\section{Pliblications Supported by Grant}

D.E. Hoglund, M.J. Aziz, S.R. Siffler, M.O. Thompson. J.Y. Tsao and P.S. Peercy, "Effect of Nonequilibrium Interface Kinetics on Cellular Breakdown of Planar Interface During Rapid Solidification of Si-Sn," Journal of Crystal Growth 109, 107-112 (1991).

D. Hoglund, M.J. Aziz, "Interface Stability During Rapid Directional Solidification," 10 appear in Materials Research Society Symposia Proceedings 205, 325-9 (1992).

P.M. Smith, J.A. West, M.J. Aziz, "Solute Trapping of Ge in Al," to appear in Materials Research Society Symposia Proceedings 205, 331-6 (1992).

\section{PERSONNEL SUPPORTED BY GRANT}

Patrick M. Smith, fifth year Ph.D. student: graduation summer 1992.

David E. Hoglund, third year Ph.D. student; expected graduation summer 1993.

Michael J. Aziz, associate professor (part-time summer salary). 

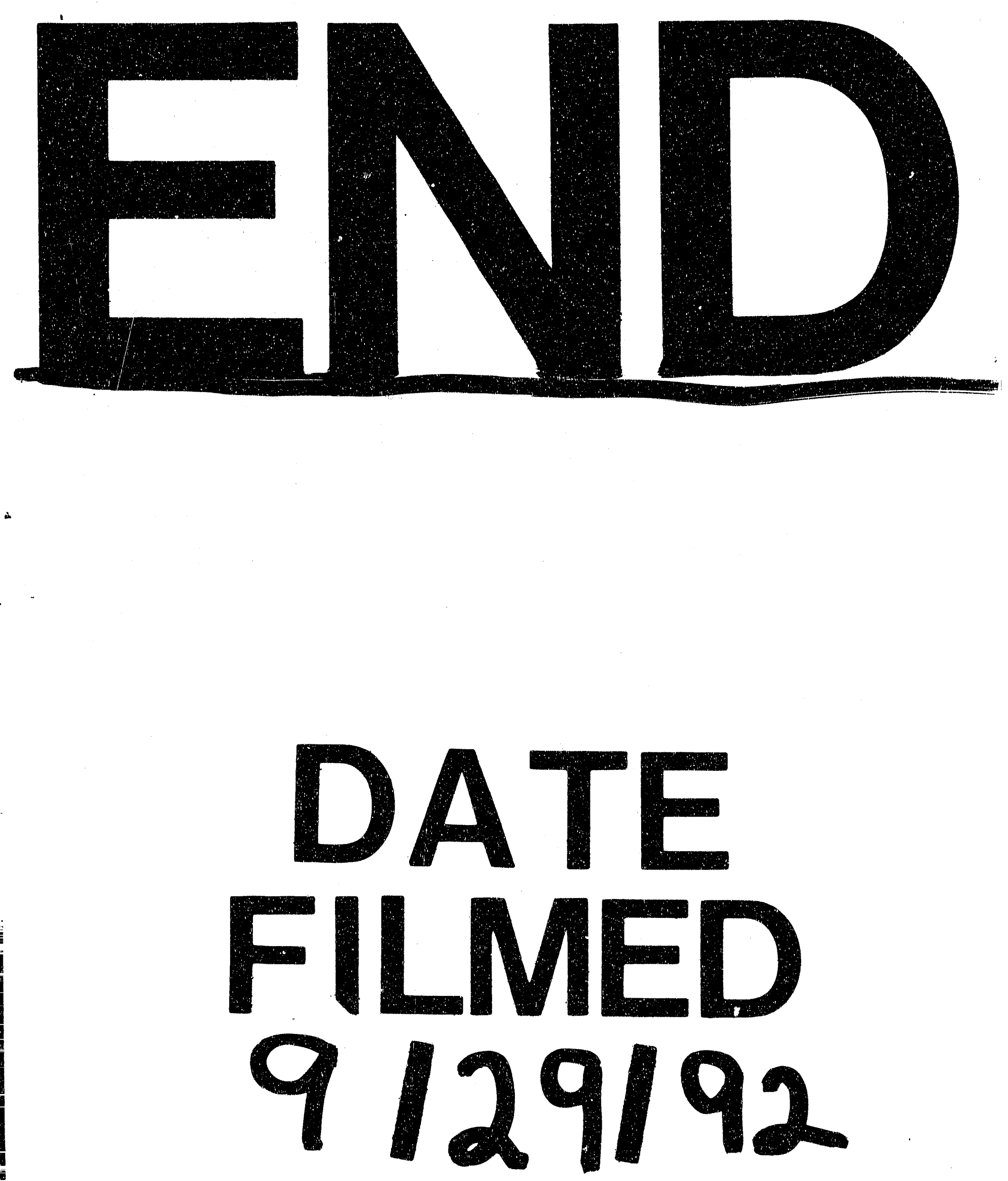
